\title{
Malignant Small Bowel Tumors: Diagnosis, Management and Prognosis
}

\author{
Tumores Malignos do Intestino Delgado: Diagnóstico, Tratamento e \\ Prognóstico
}

Hélder CARDOSO ${ }^{1,2}$, João RODRIGUES $\bigotimes^{2}$, Margarida MARQUES ${ }^{1,2}$, Armando RIBEIRO ${ }^{1,2}$, Filipe VILAS-BOAS ${ }^{1,2}$, João SANTOS-ANTUNES ${ }^{1,2}$, Eduardo RODRIGUES-PINTO' ${ }^{1,2}$, Marco SILVA ${ }^{1,2}$, José Costa MAIA ${ }^{3}$, Guilherme MACEDO ${ }^{1,2}$ Acta Med Port 2015 Jul-Aug;28(4):448-456

\begin{abstract}
Purpose: Despite being rare entities, the incidence of malignant small bowel tumors seems to be rising. The development of capsule endoscopy and balloon assisted enteroscopy provided an advance in the assessment of small bowel lesions. We aim to describe the clinical and pathological characteristics of patients with small bowel cancer and ascertain what roles these endoscopic techniques currently have.
\end{abstract}

Material and Methods: A retrospective study of patients diagnosed with small bowel cancer, from January 2010 to October 2014 , was performed. The data was submitted to statistical analysis.

Results: Of the 28 diagnosed patients, $54 \%$ were female. The mean age at diagnosis was 61 years. Adenocarcinoma was the most frequent tumor $(n=11)$, followed by sarcoma $(n=6)$, lymphoma $(n=6)$ and neuroendocrine tumors $(n=3)$. The main form of presentation was related to blood loss or intestinal obstruction. By the time of diagnosis, $46 \%$ of patients had distant metastasis/ unresectable cancer. Most of the tumors were diagnosed by endoscopic (41\%) or imaging techniques (35\%). In the first year after diagnosis, $29 \%$ of patients died. In multivariate analysis, adenocarcinoma remained an independent factor for worse survival.

Discussion: Patients with adenocarcinoma presented at late stages and with unresectable tumors, contributing to a worse outcome. A high degree of clinical suspicion for the diagnosis of small bowel cancer is necessary.

Conclusion: The characteristics of the patients were generally consistent with those described in the literature. Capsule endoscopy and balloon assisted enteroscopy are useful in the diagnosis, management and surveillance of small bowel cancer.

Keywords: Capsule Endoscopy; Intestinal Neoplasms; Portugal.

\section{RESUMO}

Introdução: Apesar de entidades raras, a incidência dos tumores malignos do intestino delgado parece estar a aumentar. O desenvolvimento da cápsula endoscópica e da enteroscopia assistida por balão permitiram um avanço na avaliação das lesões do intestino delgado. Temos como objetivo descrever as características clínicas e patológicas dos doentes com cancro do intestino delgado e averiguar o papel que estas técnicas endoscópicas assumem atualmente.

Material e Métodos: Foi realizado um estudo retrospetivo dos doentes diagnosticados com cancro do intestino delgado, desde janeiro de 2010 até outubro de 2014. Os dados foram submetidos a análise estatística.

Resultados: Dos 28 doentes diagnosticados, $54 \%$ eram do sexo feminino. A idade média ao diagnóstico foi de 61 anos. 0 tumor mais frequente foi o adenocarcinoma $(n=11)$, seguido do sarcoma $(n=6)$, linfoma $(n=6)$ e tumores neuroendócrinos $(n=3)$. A principal forma de apresentação esteve relacionada com perdas hemáticas ou obstrução intestinal. Ao diagnóstico, $46 \%$ dos doentes tinham metástases distantes/tumor irressecável. A maioria dos tumores foi diagnosticada por técnicas endoscópicas (41\%) ou imagiológicas (35\%). No primeiro ano após o diagnóstico, $29 \%$ dos doentes faleceram. Na análise multivariada, o adenocarcinoma permaneceu fator independente para pior sobrevida.

Discussão: Os doentes com adenocarcinoma apresentaram-se em estádios tardios e com tumores irressecáveis, contribuindo para um pior prognóstico. É necessário um elevado grau de suspeita clínica para o diagnóstico de cancro do intestino delgado.

Conclusão: As características dos doentes foram globalmente consistentes com o descrito na literatura. A cápsula endoscópica e a enteroscopia assistida por balão são úteis no diagnóstico, gestão e vigilância do cancro do intestino delgado.

Palavras-chave: Endoscopia por Cápsula; Neoplasias Intestinais; Portugal.

\section{INTRODUCTION}

Malignant small bowel tumors are known to be one of the rarest malignancies arising from the gastrointestinal tract. Despite this, there is evidence of the rising incidence of small bowel cancer through the last decades, with increases as high as 1.2 to 2.3 per 100000 population from 1973 to $2004 .^{1-3}$ The current 5-year survival rate in the United States is around $65 \% .{ }^{4}$ Several histological types of cancer can arise in the small bowel, but adenocarcinomas, neuroendocrine tumors, lymphomas and sarcomas consti- tute the majority of cases. ${ }^{5}$ Some tumors can also metastasize into the small intestine, either by peritoneal seeding or contiguous invasion (for example colon cancer), or by haematogenous spread (for example lung cancer or melanoma). ${ }^{6,7}$ Each histological type has its own characteristics and manifestations, making their treatment different as well. The lack of specific symptoms and clinical signs for small bowel malignancies classically delays the diagnosis and complications like active bleeding, intestinal obstruction

1. Serviço de Gastrenterologia. Centro Hospitalar de São João. Porto. Portugal.

2. Faculdade de Medicina. Universidade do Porto. Porto. Portugal.

3. Serviço de Cirurgia. Centro Hospitalar de São João. Porto. Portugal.

$\square$ Autor correspondente: João Rodrigues. jtiago.rod@gmail.com

Recebido: 06 de Abril de 2015 - Aceite: 16 de Junho de 2015 | Copyright @ Ordem dos Médicos 2015 
or perforation can be the presenting patterns. ${ }^{5,8}$ Thus, it is necessary not to disregard the suspicion of malignant small bowel tumors in clinical context, since prompt diagnosis and treatment may improve the prognosis of patients suffering from this condition. The small bowel has always been an organ difficult to access and for long the diagnosis of these tumors relied on indirect imaging procedures or surgery. ${ }^{9}$ However, in recent years, there has been much development in endoscopic techniques allowing full direct visualization of the small intestine. Video capsule endoscopy and balloon assisted enteroscopy (single or double balloon) are examples of those breakthroughs and they provided a considerable advance in both the detection and treatment of small bowel lesions. ${ }^{10-14}$ Although publications concerning small bowel tumors and their diagnostic methods have been increasing, the amount of data is still limited, particularly in Portugal. With the present work, we aim to describe the clinical and pathological characteristics of patients diagnosed with malignant small bowel tumors, in a Portuguese single center, and try to establish how these tumors are currently being managed and treated. We will also consider what roles video capsule endoscopy and balloon assisted enteroscopy have had in the diagnosis and management of such lesions.

\section{MATERIAL AND METHODS}

This is a retrospective observational study. We searched the hospital's records for all patients diagnosed with malignant small bowel tumors from January 2010 to October 2014. Lymphoma cases were only included if the tumor was a small bowel primary. Tumors involving the periampullary region, where it was not possible to exclude bilio-pancreatic origin, were not included. Three patients were excluded due to the lack of data. Therefore, the clinical files of 28 eligible patients were reviewed for the following variables: sex, age at diagnosis, clinicopathological and histological findings, haemoglobin level at admission, diagnostic investigations, treatment and outcome. All patients underwent definitive histological diagnosis. Staging of adenocarcinoma, neuroendocrine tumors and sarcomas, as well as the histological grading of neuroendocrine tumors, was based on the 7th Edition of the American Joint Committee on Cancer/Union for International Cancer Control (AJCC/UICC) staging system. ${ }^{15}$ Lymphomas were staged according to the Lugano staging system for gastrointestinal lymphomas. ${ }^{16}$ The risk assessment of progressive disease in patients with GIST was based on the Armed Forces Institute of Pathology (AFIP) criteria. ${ }^{17}$ All balloon assisted enteroscopy examinations were done using a single-balloon enteroscope. Capsule endoscopy was performed with PillCam ${ }^{\mathrm{TM}}$ SB2 or SB3. Numerical variables are presented as means and standard deviations, if data normally distributed, or as medians and interquartile ranges (IQR), if nonparametric distribution. Categorical variables are presented as percentages. Groups were compared using t-test for parametric data. The Fisher's exact test was used for categorical variables. Overall survival time was estimated from the date of histological diagnosis to the date of death or last follow-up using the KaplanMeyer method and appropriate groups were compared using the log-rank test. A multivariate analysis using Cox regression was performed, including the variables that were significant at univariate analysis. All $p$-values below 0.05 were considered statistically significant. The data was anonymized and analysed using the software IBM SPSS Statistics version 22 for Windows. This study was approved by the local ethical committee.

\section{RESULTS}

Clinical and pathological characteristics of the patients

Of the 28 patients diagnosed with malignant small bowel tumor, $46 \%(n=13)$ were male and $54 \%(n=15)$ were female. The mean age at diagnosis was $61 \pm 10$ years (range 40 - 81). The mean follow-up time since histological diagnosis was $20 \pm 18$ months. The histological types of the tumors and respective locations are summarized in Table 1. One patient had simultaneously a jejunal GIST and an ileal follicular lymphoma, accounting for a total of 29 tumors.

Although the majority of duodenal tumors were located in the proximal duodenum (D1-D2), 3 adenocarcinomas were located distally (D3-D4). Patients with jejunal tumors were significantly younger at diagnosis (mean age 54 vs. 64 years; $p=0.014$ ). The most common form of presentation was related to blood loss $(n=9)$. Of these patients, 7 presented with anaemia/occult gastrointestinal bleeding (OGIB), 1 with acute upper gastrointestinal bleeding and 1 with vaginal bleeding (GIST was in contact with the vagina). Other presenting patterns were, by decreasing order, intestinal obstruction ( $n=6)$, uncomplicated abdominal pain $(n=4)$, intestinal perforation $(n=3)$, diarrhoea $(n=$ 2 ) and obstructive jaundice $(n=1)$. Finally, 3 patients were asymptomatic at diagnosis, the tumor being found at routine examinations for other causes. The median time

Table 1 - Histological types and locations of malignant small bowel tumors

\begin{tabular}{|c|c|c|c|c|}
\hline Type of Tumor & Duodenum & Jejunum & Ileum & Total \\
\hline Adenocarcinoma & 8 & 2 & 1 & 11 \\
\hline Sarcoma & & & & 6 \\
\hline GIST & 1 & 4 & - & \\
\hline Leiomyosarcoma & - & - & 1 & \\
\hline Lymphoma & & & & 6 \\
\hline Follicular & 1 & - & 2 & \\
\hline MALT & 1 & 1 & 1 & \\
\hline Neuroendocrine & - & - & 3 & 3 \\
\hline (Metastasis) & & & & 2 \\
\hline Adenocarcinoma & - & - & 1 & \\
\hline Adenosquamous & - & - & 1 & \\
\hline Undifferentiated Tumor & - & 1 & - & 1 \\
\hline Total & 11 & 8 & 10 & 29 \\
\hline
\end{tabular}


of symptoms until the method of diagnosis was 13 days (IQR 1 - 33 days). By the time of diagnosis, 46\% $(n=13)$ of patients had distant metastasis/unresectable cancer. The mean haemoglobin at presentation was $11.0 \pm 3.3 \mathrm{~g} / \mathrm{dl}$.

When compared with the other tumors, adenocarcinomas were more commonly found within the duodenum $(p=$ $0.006)$ and had lower haemoglobin at diagnosis (9.4 vs. $12.0 \mathrm{~g} / \mathrm{dl} ; p=0.047)$. Uncomplicated abdominal pain $(\mathrm{n}=3)$ and anaemia/OGIB $(n=3)$ were the most common forms of presentation in patients with this type of tumor. At diagnosis, 4 adenocarcinomas were stage IV (distant metastasis, of which 3 were located in the liver and 1 in the peritoneum), 2 were stage IIIA, 1 was stage IIB and 1 was stage IIA. Additionally, 3 duodenal adenocarcinomas, staged IIIA or IIIB, were unresectable due to invasion of major vascular structures.

Compared to other tumors, GISTs were more common in the jejunum $(p=0.015)$ and patients with GIST were significantly younger at diagnosis (53 vs. 63 years; $p$ $=0.040)$. Two of the GISTs were staged as T4, both with distant metastasis (one in the liver, the other in the peritoneum) and graded as high-risk for progression. The other three GISTs were graded as low-risk for progression, one being staged as $\mathrm{T} 1$ and the remaining two staged as T2, none of them with distant metastasis. There was no evidence of nodal involvement in any case. Four of the GIST patients presented with blood loss symptoms and one was asymptomatic.

All diagnosed lymphomas were non-Hodgkin B-cell and 2 had multifocal small bowel lesions. Among the follicular lymphomas, two were stage I, presenting with abdominal pain or anaemia/OGIB. The other was stage IIE presenting with 2 asymptomatic ileal lesions. Of the MALT lymphomas, one presented with asymptomatic multiple duodenal polypoid lesions (stage I), and the remaining two presented with intestinal obstruction, one being stage I and the other stage $\|_{1} \mathrm{E}$.

As for patients with neuroendocrine tumors, two had multiple intestinal lesions clustered in close proximity. All neuroendocrine tumors were well differentiated at histology. One was low grade (G1) staged as T4 (largest lesion) N1M0 and presented with intestinal obstruction. The other was intermediate grade (G2), T3 (largest lesion) $\mathrm{N} 1 \mathrm{M0}$ and presented with anaemia/OGIB. The remaining neuroendocrine tumor was low grade (G1), staged as T2N1M1, with peritoneal metastasis and presenting with diarrhoea. None of the patients had been diagnosed with carcinoid syndrome.

Two of the patients with malignant small bowel tumor had metastasis in the small bowel originating from another site. One resulting from a relapsing colorectal cancer and the other from a possible pulmonary primary lesion (patient had multifocal ileal lesions of adenosquamous carcinoma). The mean tumor size was $5.0 \pm 3.2 \mathrm{~cm}$. Neuroendocrine tumors had significantly lower mean size than other tumors (2.0 vs. $5.4 \mathrm{~cm} ; p<0.001$ )

\section{Diagnostic considerations}

Most of the tumors were diagnosed by endoscopic $(41 \% ; n=12)$ or imaging techniques $(35 \% ; n=10)$. Surgery provided the primary diagnosis of 7 tumors (24\%). Of the patients to whom surgery provided diagnosis, one had an unresolving small bowel obstruction due to a jejunal MALT lymphoma and 5 had to be submitted to an emergent laparotomy [ 2 had a complete small bowel obstruction (ileal colorectal cancer metastasis and ileal adenosquamous metastasis) and 3 had an intestinal perforation (ileal leiomyosarcoma, jejunal adenocarcinoma and jejunal undifferentiated tumor)].

Computed tomography (CT) techniques were the main imaging method of diagnosis $(n=8)$, followed by ultrasound $(n=1)$ and magnetic resonance imaging $(n=1)$. These techniques diagnosed 3 duodenal tumors, 3 jejunal tumors and 4 ileal tumors.

Upper endoscopy diagnosed 6 duodenal tumors (4 adenocarcinomas, 1 MALT lymphoma and 1 follicular lymphoma) and colonoscopy diagnosed 2 tumors (a follicular lymphoma of the distal ileum and a distal duodenal adenocarcinoma invading the left colon).

The detailed role of video capsule endoscopy and balloon assisted enteroscopy in the approach of all patients is described in Table 2 and Table 3 . Video capsule endoscopy diagnosed 3 tumors in 3 patients. Two of these patients later underwent balloon assisted enteroscopy, which provided the sample for histological diagnosis in one (Patient $\mathrm{J}$ ), but in the other (Patient $\mathrm{A}$ ), due to active bleeding, biopsies could not be performed and the histological diagnosis was only obtained after surgery. The third patient (Patient C), before further study could be made, had to be submitted to an emergent laparotomy due to persistent lower gastrointestinal bleeding originating from an ileal follicular lymphoma (surgery also revealed a jejunal GIST in this patient, which was not seen in any other previous examination). Balloon assisted enteroscopy diagnosed 1 tumor (Patient $\mathrm{D}$ ). This patient had undergone a previous total gastrectomy for gastric cancer and had a Roux-en-Y anastomosis. Enteroscopic examination revealed, at the jejuno-jejunal anastomosis, a fistula to a large necrotic extraluminal tumor of gastrointestinal origin. The tumor involved the distal duodenum, the afferent loop, the retroperitoneum and the celiac trunk. In Patient $\mathrm{E}$, video capsule endoscopy was unable to complete a full small bowel visualization, probably due to slow small intestinal transit. Patient $B$ and Patient $L$ balloon assisted enteroscopy examinations were deemed as inconclusive (the endoscope was not able to proceed) due to fixed angulation of the small bowel (patient had undergone a previous subtotal colectomy for colorectal cancer) and small bowel diverticula, respectively. None of the remaining video capsule endoscopy and balloon assisted enteroscopy examinations had other described complications.

\section{Treatment and prognosis}

All patients were submitted to treatment except 


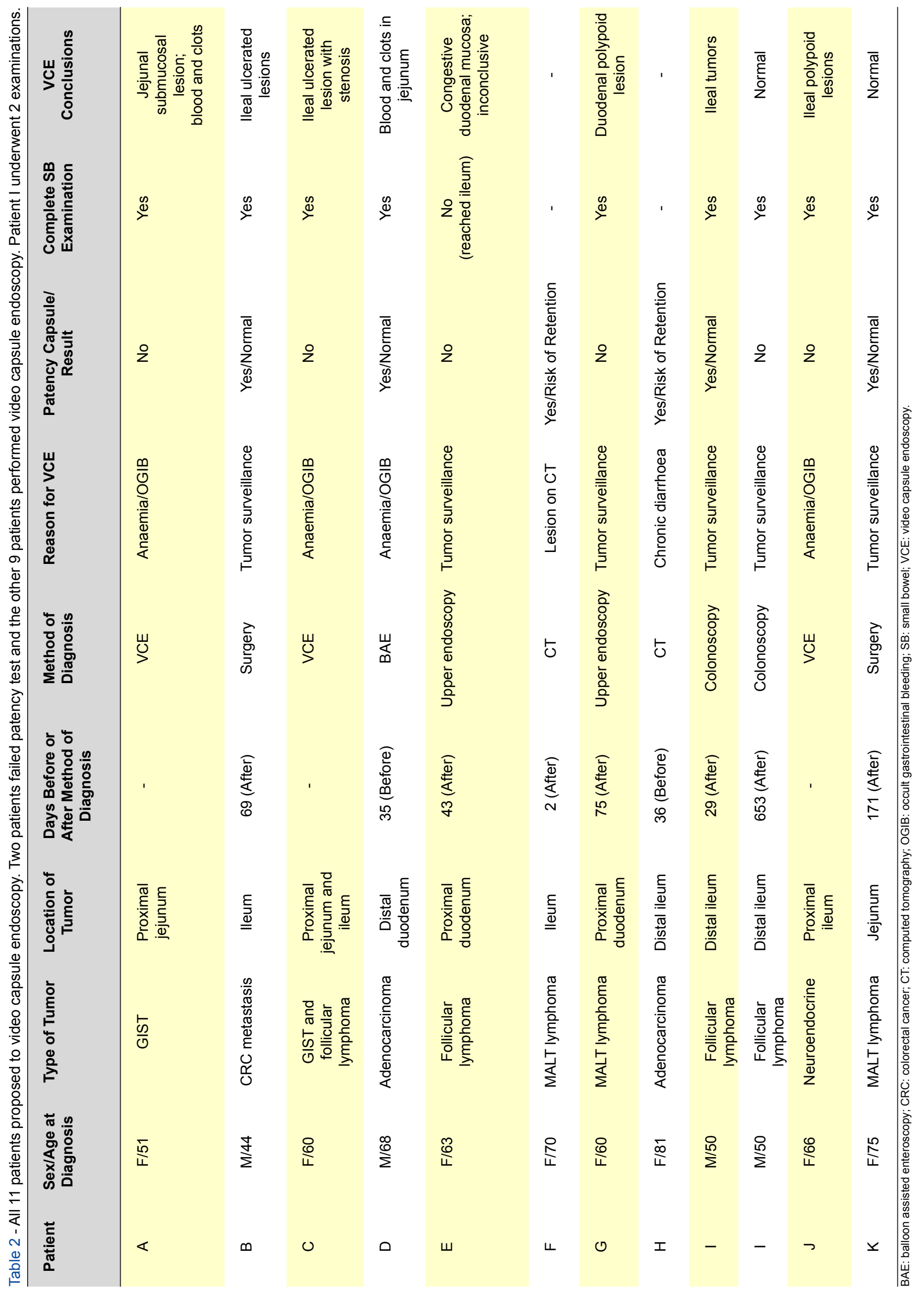




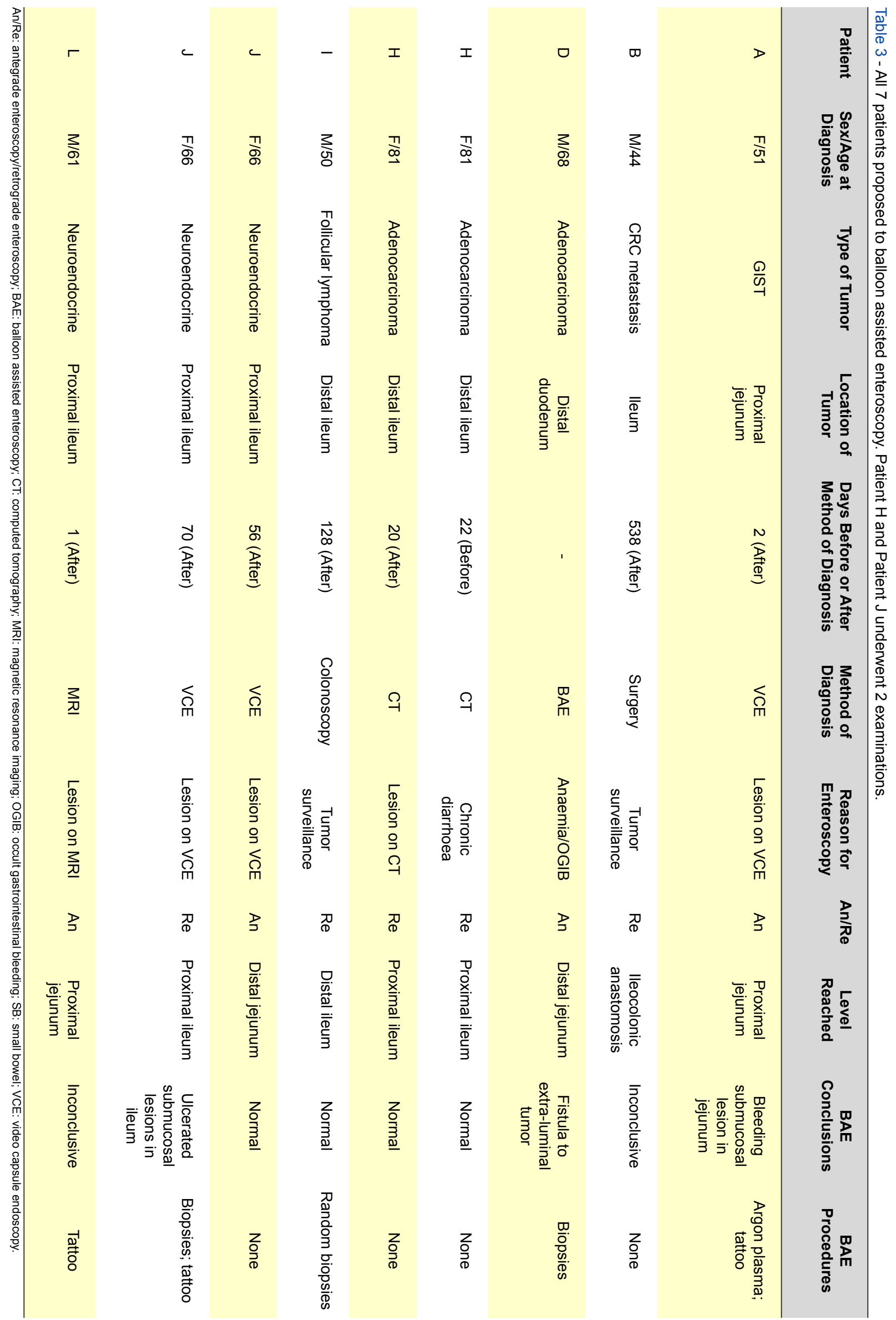


one (duodenal MALT lymphoma) to whom only tumor surveillance was advised. Six patients (21\%) underwent surgical resection alone (1 adenocarcinoma, 2 neuroendocrine tumors, 2 GISTs, 1 MALT lymphoma) and 2 patients were only proposed to chemotherapy (2 follicular lymphomas). Ten patients (36\%) underwent surgical resection plus an additional therapy, which consisted in adjuvant chemotherapy in 6 patients ( 3 adenocarcinomas, 1 colorectal cancer metastasis, 1 MALT Iymphoma and 1 undifferentiated tumor), Imatinib in 3 patients with GIST (2 had distant metastasis and 1 had ruptured the intestinal serosa) and somatostatin analogues in 1 patient with metastasized neuroendocrine tumor. The remaining 9 patients $(32 \%)$ received palliative surgery/chemotherapy.

The mean estimated overall survival was 33 months (95\% Cl 24.0 - 42.6), (Fig. 1). A total of 11 patients (39\%) died during follow-up and 8 patients (29\%) died in the first year after diagnosis. All deaths were due to oncological complications. Patients who have not died during follow-up had stable or remitting disease at the date of last followup. Patients with adenocarcinoma had significantly lower mean survival than patients with other types of tumors (14 vs. 44 months; $p=0.006$ ), (Fig. 2). There was no statistical difference in survival between patients with duodenal, jejunal or ileal tumors. Patients with distant metastasis/ unresectable tumor at diagnosis had lower mean survival (20 vs. 46 months; $p=0.010$ ). In multivariate analysis, adenocarcinoma remained an independent factor for worse survival (OR 8.5; 95\% CI 1.8 - 41.5; $p=0.007$ ).

\section{DISCUSSION}

Considering the length and mucosal surface area represented by the small intestine, it is interesting to note that small bowel cancer accounts for less than $5 \%$ of all gastrointestinal malignancies. ${ }^{1}$ There are several possible explanations for the rarity of these tumors when compared with the large bowel, including the protective effect of higher levels of IgA and the more rapid transit times in small

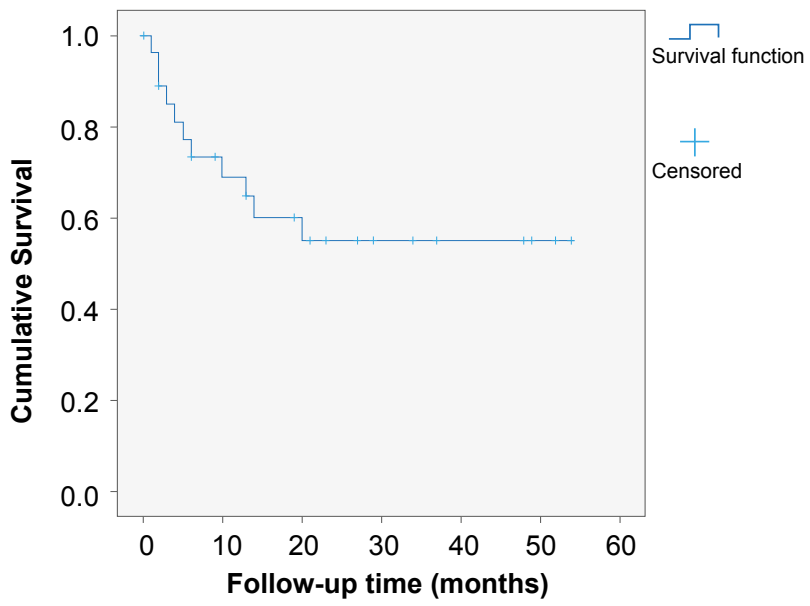

Figure 1 - Overall survival of all patients with malignant small bowel tumors (mean 33 months; $95 \% \mathrm{Cl} 24.0$ - 42.6). intestine, reducing mucosal exposure to carcinogens..$^{5,18}$ The lower bacterial load and the more efficient response to oxidative stress may also be contributing factors. ${ }^{19}$ Some predisposing conditions are known to be linked with small bowel cancer development. Hereditary syndromes (familial adenomatous polyposis, Lynch syndrome, Peutz-Jeghers syndrome), inflammatory bowel disease, coeliac disease, certain life style behaviours and even specific infectious agents are examples of factors associated with increased risk. ${ }^{20,21}$ Small bowel cancer seems to be more common in industrialized regions (Western Europe, North America and Oceania). ${ }^{22}$ Evidence has shown an overall incidence increase in the last decades, particularly due to a rise in neuroendocrine tumors and duodenal adenocarcinomas. ${ }^{1-3}$ According to the latest oncological records, incidence in Portugal also seems to be rising, with crude incidence rates per 100000 population of 1.0 in 2001, 1.5 in 2005 and 1.7 in $2008 .^{23}$ It is unknown if this national increase represents a clear incidence rise, or if it may be due to the improvement in diagnostic methods or to disease underreporting in earlier years.

As most cancers, small bowel malignancies tend to appear in older ages, the mean age being in the sixth decade of life. ${ }^{24,25}$ Although literature describes small bowel cancer as being male predominant, this is not found in all series. $^{24}$

The preferred location for small bowel cancer largely depends on the tumor's histological type. Adenocarcinomas tend to be more common in the duodenum, GISTs in the jejunum and neuroendocrine tumors in the ileum, while different subgroups of lymphomas have different site preferences. ${ }^{1,20,21,26}$ Our results are consistent with this distribution. We did not found any statistical significant difference in survival between patients with duodenal, jejunal or ileal tumors. In fact, Talamonti et al. suggested that the natural history of small bowel cancer depended more on disease stage and certain biological factors than on the site of origin. ${ }^{26}$

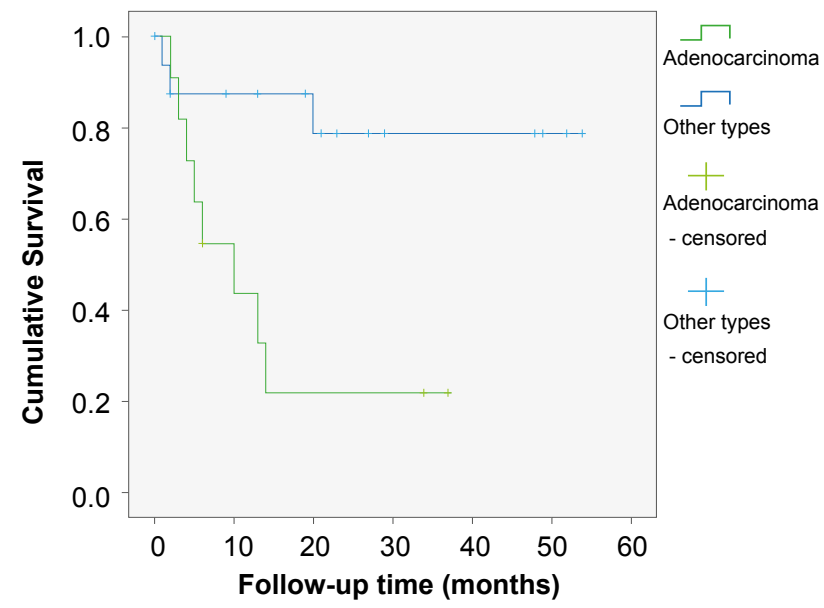

Figure 2 - Overall survival of patients with adenocarcinoma compared with patients with other types of tumors (mean $14 \mathrm{vs} .44$ months; $p=0.006$ ). 
Adenocarcinoma is generally considered the most frequent type of cancer arising from the small bowel (around $40 \%$ of cases), despite some studies claiming it is being surpassed by neuroendocrine tumors. ${ }^{24,27}$ In a study of 491 cases of small bowel adenocarcinoma, advanced age, male sex, higher stage, residual disease after resection, and a lymph node ratio of $50 \%$ or greater were predictors of worse survival. ${ }^{28}$ Our study revealed that more than half of patients with adenocarcinoma presented at stage IV or with unresectable lesions. This can be a contributing factor to the lower survival of adenocarcinoma patients when compared to other types of tumors. The more advanced oncological stage could also explain the lower haemoglobin at diagnosis of patients with adenocarcinoma.

Approximately $10-15 \%$ of small bowel cancers are sarcomas, with GISTs representing the majority of cases. ${ }^{22}$ Gastrointestinal bleeding is the most common presenting pattern. ${ }^{29}$ Despite often being intramural, serosal or submucosal nodules, GISTs can result in mucosal ulceration and, in rare cases, grow in an intraluminal direction causing intestinal obstruction. ${ }^{30}$ They rarely metastasize to lymph nodes and some are discovered incidentally. ${ }^{31}$ Compared to other histological types, GISTs and lymphomas tend to occur at younger ages. ${ }^{24}$ Our finding that jejunal tumors occurred at younger ages, can possibly be explained by GISTs being more common in the jejunum.

Primary gastrointestinal non-Hodgkin lymphoma is the most frequent form of extra-nodal lymphoma. Lymphomas constitute $15-20 \%$ of all small intestinal cancers, MALT lymphoma being one of the most common. ${ }^{22}$ Particularly MALT lymphoma and follicular lymphoma seem to have a predilection for multifocality. ${ }^{21}$ Although our study did not consider such cases, it is important to note that gastrointestinal lymphomas are usually secondary to the widespread of primary nodal diseases. ${ }^{21}$

More than $25 \%$ of neuroendocrine tumors are multifocal with clustered lesions in close proximity. ${ }^{32}$ Although neuroendocrine tumors had significantly lower mean size than other types of tumors, we found that one patient had already hepatic metastasis at diagnosis. In fact, even infracentimetric lesions can metastasize (mainly to the mesentery and the liver), becoming more prone to cause carcinoid syndrome. ${ }^{32}$

Treatment options for small bowel cancer largely depend on the tumor's histological type and location. ${ }^{33}$ Surgical resection with clear margins and regional lymph node dissection represents the curative therapy of choice in most of cases. Data regarding the use of adjuvant chemotherapy for adenocarcinoma is still controversial. ${ }^{20}$ Chemotherapy or radiation can be the first choice in various subgroups of lymphomas but surgical treatment can be required in more advanced stages or if complications, such as intestinal obstruction or perforation, are present. ${ }^{33}$ In some cases of indolent lymphoma at early stages, a wait and watch policy may be advocated. ${ }^{21}$ Although wide resection is requested in case of infiltration of continuous organs, small GISTs can effectively be treated by local excision alone. ${ }^{34}$
Lymph node resection is generally not advocated for these mesenchymal tumors. In GISTs and neuroendocrine tumors, tyrosine-kinase inhibitors and somatostatine analogues, respectively, are also currently available treatment options. These therapies came to significantly improve survival, particularly in patients with GISTs. ${ }^{35}$

When there is a suspicion of a small intestinal lesion, several imaging methods are within our reach. Computed tomography and magnetic resonance imaging techniques can be useful in detecting those lesions, particularly with the advent of high-resolution images. ${ }^{8,36}$ Despite this, they cannot provide precise data about the intestinal mucosa and can miss some lesions, particularly if small and flat. Endoscopic methods such as upper endoscopy and colonoscopy can be appropriate if the lesion is located as close as the proximal duodenum or as far as the terminal ileum, but the rest of the small bowel cannot be accessed.

Wireless video capsule endoscopy was introduced in 2001, and since then has been largely used as a noninvasive means of visualizing the entire length of the small bowel. ${ }^{37}$ Our results reinforce the fact that this technique is capable of diagnosing tumors or, at least, provide us with evidence of its presence, being a useful means in clinical practice. It is important to note that video capsule endoscopy was also applied to surveillance of the small bowel following tumor diagnosis, during or after treatment. This was particularly evident in patients with lymphomas. As these tumors can be multifocal, entire small bowel examination is of value. However, video capsule endoscopy has some disadvantages, including the inability to motion control or perform interventions, the potential for incidental findings and the risk of missing to identify some lesions, particularly if suboptimal bowel preparation. ${ }^{38}$ Capsule retention may be one of the complications and preclude its use in patients with suspected stenosis. ${ }^{38}$ The patency capsule test may be applied if strictures or obstruction are suspected. Some of the video capsule limitations were evident in this series.

Balloon assisted enteroscopy allows surpassing some of the video capsule disadvantages. It can be executed by oral route or anal route based on the presumed location of the lesion. In our study, balloon assisted enteroscopy performed biopsies, treated bleeding lesions and was capable of discovering tumors not seen on video capsule endoscopy, as described in literature. ${ }^{39}$ However, this technique is not infallible, as certain technical limitations can result in an inconclusive small bowel examination. Zagorowicz et al, proposed that balloon assisted enteroscopy should be the next diagnostic tool after a normal or non significant capsule endoscopy examination, when symptoms strongly suggest a small bowel lesion. ${ }^{40}$ Many of the studies concerning small bowel tumors and balloon assisted enteroscopy refer to the double-balloon method. In our center, singleballoon enteroscopy was used. According to the literature, there seems to be no difference in the diagnostic accuracy between these two techniques. ${ }^{41,42}$

At this point, several studies have evaluated the usefulness and diagnostic accuracy of both video capsule 
endoscopy and balloon assisted enteroscopy in the approach of malignant small bowel tumors. ${ }^{10,11,14}$ Two Portuguese series also support this finding, despite being limited to a smaller sample size. ${ }^{12,13}$ In our center, $46 \%$ of the patients had distant metastasis/unresectable cancer at diagnosis, contributing, as expected, to a worse outcome. An advanced oncological stage and presenting patterns such as intestinal obstruction, perforation or active bleeding, could explain the low time between symptoms onset and tumor diagnosis described in the results. On the other hand, unspecific symptoms, such as anaemia/OGIB, diarrhoea or abdominal pain, not always lead to small bowel investigation and are prone to be devalued by both patients and clinicians, mainly after upper endoscopy and colonoscopy. For this reason, we assume that a high degree of clinical suspicion for small bowel cancer is necessary and useful, particularly for patients presenting with unspecific symptoms. Here, enteroscopic methods can prove their capabilities and advantages in the prompt diagnosis of small bowel cancer.

Although, to our knowledge, this is the Portuguese study including more cases of small bowel cancer, one of the major limitations is still the small sample size. Future investigations, specifically multi-center studies performed over a longer period of time, could be of interest, giving a more national overview concerning this subject.

\section{CONCLUSION}

Overall, we were able to describe the characteristics of malignant small bowel tumors diagnosed in a single center and conclude that they are generally consistent with those described in the literature. A high degree of suspicion for diagnosis is necessary, as some patients present with unspecific symptoms. Patients with adenocarcinoma and presenting at late stages have a worse outcome. Thus, attempting a prompt diagnosis is of interest, in order to improve survival. Video capsule endoscopy and balloon assisted enteroscopy can be useful tools, not only in the diagnosis, but also in the management and surveillance of small bowel cancer.

\section{PROTECTION OF HUMANS AND ANIMALS}

The authors declare that the procedures were followed according to the regulations established by the Clinical Research and Ethics Committee and to the Helsinki Declaration of the World Medical Association.

\section{DATA CONFIDENTIALITY}

The authors declare having followed the protocols in use at their working center regarding patient's data publication.

\section{CONFLICTS OF INTEREST}

The authors state no conflict of interests and have received no payment to perform this work.

\section{FUNDING SOURCES}

No subsidies or grants contributed to this work.

\section{REFERENCES}

1. Haselkorn T, Whittemore AS, Lilienfeld DE. Incidence of small bowel cancer in the United States and worldwide: geographic, temporal, and racial differences. Cancer Causes Control. 2005;16:781-7.

2. Shack LG, Wood HE, Kang JY, Brewster DH, Quinn MJ, Maxwell JD, et al. Small intestinal cancer in England \& Wales and Scotland: time trends in incidence, mortality and survival. Aliment Pharmacol Ther. 2006;23:1297-306.

3. Lu Y, Frobom R, Lagergren J. Incidence patterns of small bowel cancer in a population-based study in Sweden: increase in duodenal adenocarcinoma. Cancer Epidemiol. 2012;36:e158-63.

4. National Cancer Institute. SEER Stat Fact Sheets: Small Intestine Cancer [Internet homepage]; [accessed 2015 Feb 25]. Available at: http://seer.cancer.gov/.

5. Reynolds I, Healy P, McNamara DA. Malignant tumours of the small intestine. Surgeon. 2014;12:263-70.

6. Bugiantella W, Cavazzoni E, Graziosi L, Valiani S, Franceschini MS, Donini A. Small bowel metastasis from lung cancer: a possible cause of acute abdomen. Case report and literature review. G Chir. 2011;32:120-2.

7. Vaz PS, Usurelu S, Monteiro A, Correia S, Gouveia A, Loureiro A. Small bowel metastatic of malignant melanoma: a rare cause of lower gastrointestinal bleeding. Acta Med Port. 2011;24:179-82.

8. Sailer J, Zacherl J, Schima W. MDCT of small bowel tumours. Cancer Imaging. 2007;7:224-33.

9. Pennazio M, Rondonotti E, de Franchis R. Capsule endoscopy in neoplastic diseases. World J Gastroenterol. 2008;14:5245-53.

10. Rondonotti E, Pennazio M, Toth E, Menchen P, Riccioni ME, De Palma GD, et al. Small-bowel neoplasms in patients undergoing video capsule endoscopy: a multicenter European study. Endoscopy. 2008;40:488-95.

11. Akamatsu T, Kaneko $\mathrm{Y}$, Ota $\mathrm{H}$, Miyabayashi H, Arakura N, Tanaka E. Usefulness of double balloon enteroscopy and video capsule endoscopy for the diagnosis and management of primary follicular lymphoma of the gastrointestinal tract in its early stages. Dig Endosc. 2010;22:33-8.

12. de Mascarenhas-Saraiva MN, da Silva Araujo Lopes LM. Small-bowel tumors diagnosed by wireless capsule endoscopy: report of five cases. Endoscopy. 2003;35:865-8.

13. Almeida N, Figueiredo P, Lopes S, Gouveia H, Leitao MC. Doubleballoon enteroscopy and small bowel tumors: a South-European single-center experience. Dig Dis Sci. 2009;54:1520-4.

14. Cheung DY, Lee IS, Chang DK, Kim JO, Cheon JH, Jang BI, et al. Capsule endoscopy in small bowel tumors: a multicenter Korean study. J Gastroenterol Hepatol. 2010;25:1079-86.

15. Edge SB, Byrd DR, Compton CC, Fritz AG, Greene FL, Trotti A, editors. AJCC (American Joint Committee on Cancer) Cancer Staging Manual. $7^{\text {th }}$ ed. New York: Springer; 2010.

16. Rohatiner A, d'Amore F, Coiffier B, Crowther D, Gospodarowicz $M$, Isaacson $P$, et al. Report on a workshop convened to discuss the pathological and staging classifications of gastrointestinal tract lymphoma. Ann Oncol. 1994;5:397-400.

17. Miettinen M, Lasota J. Gastrointestinal stromal tumors: pathology and prognosis at different sites. Semin Diagn Pathol. 2006;23:70-83.

18. Cerutti $A$, Rescigno $M$. The biology of intestinal immunoglobulin $A$ responses. Immunity. 2008;28:740-50.

19. Sanders LM, Henderson CE, Hong MY, Barhoumi R, Burghardt RC, small intestine may contribute to greater cancer susceptibility. Cancer Lett. 2004;208:155-61.

20. Aparicio T, Zaanan A, Svrcek M, Laurent-Puig P, Carrere N, Manfredi $\mathrm{S}$, et al. Small bowel adenocarcinoma: epidemiology, risk factors, diagnosis and treatment. Dig Liver Dis. 2014;46:97-104.

21. Ghimire P, Wu GY, Zhu L. Primary gastrointestinal lymphoma. World J Gastroenterol. 2011;17:697-707. Carroll RJ, et al. Pro-oxidant environment of the colon compared to the 
22. Pan SY, Morrison $\mathrm{H}$. Epidemiology of cancer of the small intestine. World J Gastrointest Oncol. 2011;3:33-42.

23. Instituto Português de Oncologia do Porto [Internet homepage] [accessed 2015 Feb 27]. Available at: http://www.ipoporto.pt/.

24. Hatzaras I, Palesty JA, Abir F, Sullivan P, Kozol RA, Dudrick SJ, et al. Small-bowel tumors: epidemiologic and clinical characteristics of 1260 cases from the connecticut tumor registry. Arch Surg. 2007;142:22935.

25. Honda W, Ohmiya N, Hirooka Y, Nakamura M, Miyahara R, Ohno E, et al. Enteroscopic and radiologic diagnoses, treatment, and prognoses of small-bowel tumors. Gastrointest Endosc. 2012;76:344-54.

26. Talamonti MS, Goetz LH, Rao S, Joehl RJ. Primary cancers of the small bowel: analysis of prognostic factors and results of surgical management. Arch Surg. 2002;137:564-70; discussion 70-1.

27. Bilimoria KY, Bentrem DJ, Wayne JD, Ko CY, Bennett CL, Talamonti MS. Small bowel cancer in the United States: changes in epidemiology, treatment, and survival over the last 20 years. Ann Surg. 2009;249:6371.

28. Halfdanarson TR, McWilliams RR, Donohue JH, Quevedo JF. A singleinstitution experience with 491 cases of small bowel adenocarcinoma. Am J Surg. 2010;199:797-803.

29. Miettinen M, Lasota J. Gastrointestinal stromal tumors: review on morphology, molecular pathology, prognosis, and differential diagnosis. Arch Pathol Lab Med. 2006;130:1466-78.

30. McLaughlin PD, Maher MM. Primary malignant diseases of the small intestine. Am J Roentgenol. 2013;201:W9-14.

31. Miettinen M, Lasota J. Histopathology of gastrointestinal stromal tumor. J Surg Oncol. 2011;104:865-73.

32. Strosberg J. Neuroendocrine tumours of the small intestine. Best Pract Res Clin Gastroenterol. 2012;26:755-73.
33. Coco C, Rizzo G, Manno A, Mattana C, Verbo A. Surgical treatment of small bowel neoplasms. Eur Rev Med Pharmacol Sci. 2010;14:327-33.

34. Goh BK, Chow PK, Kesavan S, Yap WM, Wong WK. Outcome after surgical treatment of suspected gastrointestinal stromal tumors involving the duodenum: is limited resection appropriate? J Surg Oncol. 2008;97:388-91.

35. Demetri GD, von Mehren M, Antonescu CR, DeMatteo RP, Ganjoo KN Maki RG, et al. NCCN Task Force report: update on the management of patients with gastrointestinal stromal tumors. J Natl Compr Canc Netw. 2010;8:S1-41.

36. Anzidei M, Napoli A, Zini C, Kirchin MA, Catalano C, Passariello R. Malignant tumours of the small intestine: a review of histopathology, multidetector CT and MRI aspects. Br J Radiol. 2011;84:677-90.

37. Hale MF, Sidhu R, McAlindon ME. Capsule endoscopy: current practice and future directions. World J Gastroenterol. 2014;20:7752-9.

38. Leighton JA. The role of endoscopic imaging of the small bowel in clinical practice. Am J Gastroenterol. 2011;106:27-36.

39. Chong AK, Chin BW, Meredith CG. Clinically significant small-bowe pathology identified by double-balloon enteroscopy but missed by capsule endoscopy. Gastrointest Endosc. 2006;64:445-9.

40. Zagorowicz ES, Pietrzak AM, Wronska E, Pachlewski J, Rutkowski P, Kraszewska E, et al. Small bowel tumors detected and missed during capsule endoscopy: single center experience. World J Gastroenterol. 2013;19:9043-8.

41. Domagk D, Mensink P, Aktas H, Lenz P, Meister T, Luegering A, et al Single- vs. double-balloon enteroscopy in small-bowel diagnostics: a randomized multicenter trial. Endoscopy. 2011;43:472-6.

42. Lenz P, Domagk D. Double vs. single-balloon vs. spiral enteroscopy. Best Pract Res Clin Gastroenterol. 2012;26:303-13. 
Hélder CARDOSO, João RODRIGUES, Margarida MARQUES, Armando RIBEIRO, Filipe VILAS-BOAS, João SANTOS-ANTUNES, Eduardo RODRIGUES-PINTO, Marco SILVA, José Costa MAIA, Guilherme MACEDO

\section{Malignant Small Bowel Tumors: Diagnosis, Management and Prognosis}

Acta Med Port 2015:28:448-456

Publicado pela Acta Médica Portuguesa, a Revista Científica da Ordem dos Médicos

Av. Almirante Gago Coutinho, 151

1749-084 Lisboa, Portugal.

Tel: +351218428 215

E-mail: submissao@actamedicaportuguesa.com

www.actamedicaportuguesa.com

ISSN:0870-399X | e-ISSN: 1646-0758

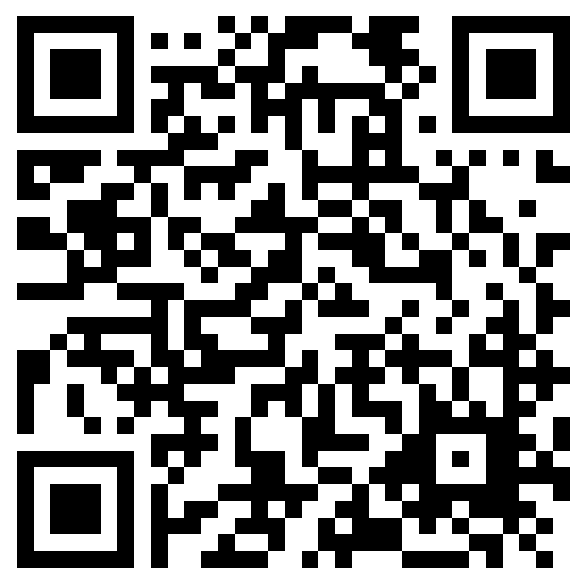

